\title{
A note on the Companion to A Historical Phonology of English
}

A Companion to this book is available at http://www.euppublishing. $\mathrm{com} /$ page/ETOTELAdvanced/Minkova. The Companion includes additional readings, exercises, comments and further resources. Online resources will be indicated in the text by the icon $\underline{ }$. 
In loving memory of

Robert Stockwell

(12 June 1925-28 October 2012) 